Journal of
Treatment Techniques $\quad \begin{gathered}\text { J. Environ. Treat. Tech. } \\ \text { ISSN: } 2309-1185 \\ \text { Techniques } \\ \text { Journal web link: http://www.jett.dormaj.com } \\ \text { https://doi.org/10.47277/JETT/8(4)1278 }\end{gathered}$

\title{
Phytoconstituents from the Aerial Parts of Salvia dracocephaloides Boiss. and their Biological Activities
}

\author{
Salar Hafez Ghoran ${ }^{1,2}$, Omidreza Firuzi², Amir Reza Jassbi2* \\ ${ }^{1}$ Department of Chemistry, Faculty of Basic Sciences, Golestan University, Gorgan 4913815759, Iran \\ ${ }^{2}$ Medicinal and Natural Products Chemistry Research Center, Shiraz University of Medical Sciences, Shiraz 7134853734, Iran
}

Received: 11/07/2020 Accepted: 04/09/2020 Published: 20/12/2020

\begin{abstract}
MTT colorimetric cytotoxic bioassay, solvent fractionation and chromatographic purification of an $80 \%$ methanol extract of Salvia dracocephaloides, led to isolation and identification of eight compounds, including 5-hydroxy-3,6,7,3',4'-pentamethoxyflavone (1), cynaroside (2), salvigenin (3), eupatorin (4), cirsimaritin (5), $\beta$-sitosterol (6), oleanolic acid (7), and ursolic acid (8). The structures of the compounds were characterized using spectroscopic analyses including HRESI-MS, ${ }^{1} \mathrm{H}$ and ${ }^{13} \mathrm{C}-\mathrm{NMR}$ and comparison with those previously reported in the literature. The biological activities of 1 and 2, including their cytotoxicity against MCF-7 human breast cancer cell line and DPPH free radicals scavenging effect were studied in vitro. Compound 1 showed stronger cytotoxicity; IC 50 of $7.2 \mu \mathrm{g} / \mathrm{mL}$ compared to that obtained for 2 ; $\mathrm{IC}_{50}$ of $15.5 \mu \mathrm{g} / \mathrm{mL}$. While, compound 2, with $3^{\prime}, 4^{\prime}$ dihydroquinol functionality, displayed higher DPPH radical inhibitory activity with an $\mathrm{IC}_{50}$ of $10.7 \mu \mathrm{g} / \mathrm{mL}$ compared to that measured for $1 ; 48.8 \mu \mathrm{g} / \mathrm{mL}$.
\end{abstract}

Keywords: Salvia dracocephaloides, Lamiaceae, Cytotoxicity, DPPH radical scavenging activity, Polymethoxyflavones

\section{Introduction}

Salvia L. (Sage) is one of the greatest genus of the perennial and annual plants among the family Lamiaceae and distributed around the world. The genus Salvia or "Maryam-Goli" in Persian includes 62-reported species in Iran which 17 of them are endemic and wildly grown in different parts of Iran $[1,2$, 3]. Sages are rich in various specialized metabolites including terpenoids, sterols, phenolics including flavonoids, lignans, and phenylpropanoids $[4,5]$. Salvia species are used in the folk medicine in different parts of the world. For instance, $S$. miltiorrihza; red sage, Danshen, S. officinalis; sage, and $S$. sclarea; clary sage are the most common species worldwide and S. hydrangea, S. macrosiphon, and S. mirzayanii are the Iranian ehtnopharmacologically important ones [6]. In addition to their use in folk medicine sage plants produce metabolites with various biological activities such as antioxidant, antibacterial, antiviral, antifungal, antileishmanial, antimalarial, antispasmodic, anti-inflammatory, anti-diabetic, cytotoxic, and insecticidal activities $[4,5,7]$.

As our ongoing research on the Iranian sages for their anticancer metabolites, we have subjected $S$. dracocephaloides to phytochemical analyses. S. dracocephaloides known as "Maryam-Goli Tamashaei" in Persian is a shrubby perennial herb 25 to $40 \mathrm{~cm}$ tall, with small purple flowers which grows in rocky and mountainous regions of Caucasus and Iran [2]. The synonymous relationship between $S$. hydrangea and $S$. dracocephaloides has been ruled out by their phenotypic differences and various essential oils composition $[2,8]$. The major constituents of the oil of $S$. dracocephaloides are camphor, 1,8-cineole, and camphene [9], while those detected in the oil of $S$. hydrangea were detected as $\alpha$ - and $\beta$-pinene, $p$ - cymene, linalool, and the sesquiterpenes; $\beta$-caryophyllene and spathulenol [10]. Except the antioxidant potential, expressed as DPPH radical scavenging activity of aqueous methanol extract of $S$. dracocephaloides, there were no other report on the chemical properties of the plant in the literature [9].

Hence, the main objective of the present study is the isolation and structure elucidation of the phytochemicals followed by reporting the cytotoxic activities of various extracts and the unexplored isolated phytochemicals. To the best of our knowledge this is the first report of Salvia dracocephaloides compounds including 5-hydroxy-3,6,7,3',4'pentamethoxyflavone; 1 [11], cynaroside; 2 [12], salvigenin; 3 [13], eupatorin; 4 [14], cirsimaritin; 5 [13], $\beta$-sitosterol; 6 [15], oleanolic acid; $\mathbf{7}$, and ursolic acid; 8 [16] in the cytotoxic chloroform soluble fraction of the $80 \%$ methanol extract (Figure 1).

\section{Materials and Methods \\ 2.1. General Experimental Procedures}

All organic solvents including $n$-hexane, dichloromethane (DMC), chloroform $\left(\mathrm{CHCl}_{3}\right)$, ethyl acetate (EtOAc), acetone, $n$-butanol $(n-\mathrm{BuOH})$, methanol $(\mathrm{MeOH})$, were commercially purchased and applied without any further purification. TLC sheets $\left(20 \times 20 \mathrm{~cm}\right.$; pre-coated silica gel $60 \mathrm{~F}_{254}$; Merck, Germany) along with silica gel (70-230 and 230-400 mesh; Merck, Germany) were used for analytical TLC and column chromatography, respectively. TLC spots were detected using anisaldehyde/sulphuric acid reagent followed by heating. HRESIMS was recorded on MicrOTOF-Q II mass spectrometer equipped with an ESI source (Bruker Daltonik, Bremen, Germany). *Corresponding author: Amir Reza Jassbi, Medicinal and Natural Products Chemistry Research Center, Shiraz University of Medical
Sciences, Shiraz 7134853734, Iran. E-mail address: jassbiar@ sums.ac.ir. Tel: +98 7132303872 and Fax: +98 7132332225 
<smiles>COc1ccc(-c2oc3cc(OC)c(OC)c(O)c3c(=O)c2-c2ccc(OC)c(OC)c2)cc1O</smiles>

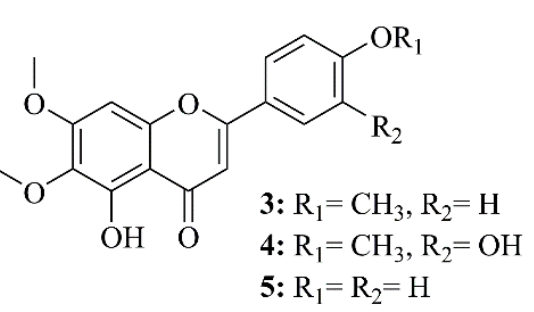<smiles>CCC(CC[C@@H](C)C1CCC2C3CC=C4CC(O)CC[C@]4(C)C3CCC21C)C(C)C</smiles><smiles>CC1(C)CC[C@]2(C(=O)O)CC[C@]3(C)C(=CC[C@@H]4[C@@]5(C)CC[C@H](O)C(C)(C)C5CC[C@]43C)C2C1</smiles><smiles>CC1CC[C@]2(C(=O)O)CC[C@]3(C)C(=CC[C@@H]4[C@@]5(C)CC[C@H](O)C(C)(C)C5CC[C@]43C)C2C1C</smiles>

Figure 1: Chemical structures of isolated compounds, 1-8, from S. dracocephaloides Boiss

1D and 2D NMR spectra were performed on a Bruker Biospin $\mathrm{GmbH}$ spectrometer $\left({ }^{1} \mathrm{H}\right.$ at $300 \mathrm{MHz}$ and ${ }^{13} \mathrm{C}$ at 75 $\mathrm{MHz},{ }^{1} \mathrm{H}$ at $400 \mathrm{MHz}$ and ${ }^{13} \mathrm{C}$ at $100 \mathrm{MHz}$ and ${ }^{1} \mathrm{H}$ at $500 \mathrm{MHz}$ and ${ }^{13} \mathrm{C}$ at $125 \mathrm{MHz}$ ). All NMR chemical shifts were expressed in ppm related to TMS signal at $0.00 \mathrm{ppm}$ as internal reference.

\subsection{Plant Materials}

The aerial parts of Salvia dracocephaloides Boiss. were collected in the flowering season (June 2017) from Marand to Jolfa road (GPS, $38^{\circ} 44^{\prime} \mathrm{N} / 45^{\circ} 36^{\prime} \mathrm{E}$, at an altitude of $1300 \mathrm{~m}$ ), East Azerbaijan Province, Iran and botanically characterized by Mr. Mehdi Zare and Dr. Mojtaba Assadollahi, the plant taxonomists in Medicinal and Natural Products Chemistry Research Center (MNCRC). A voucher specimen; No. PC-963-8-28.1, of the plant was deposited at the Herbarium MNCRC.

\subsection{Extraction procedure}

The air-dried powder of $S$. dracocephaloides aerial parts $(300 \mathrm{~g})$ was extracted in methanol water $(8: 2)$ solvent using maceration method for $48 \mathrm{~h}(3 \times 2 \mathrm{~L})$. After evaporation of the solvent by rotary evaporator, the crude extract $(71.68 \mathrm{~g})$ was partitioned in water $(1 \mathrm{~L})$ and organic solvents $(3 \times 1 \mathrm{~L})$ in the order of increasing polarity; $n$-hexane, chloroform, ethyl acetate, and $n$-butanol. All of the organic layers and the remaining water fraction were concentrated under reduced pressure and stored in refrigerator at $-20{ }^{\circ} \mathrm{C}$ for further phytochemical and biological studies.

\subsection{Purification of the phytochemicals}

The $\mathrm{CHCl}_{3}$ and $n$-hexane fractions showed the highest cytotoxic activity against MOLT-4 cell line (Table 1). Therefore, the former fraction was chosen for further purification of its constituents, while the latter one was found to be out of interest due to the presence of high levels of fatty acids, waxes, carotenoids, and chlorophylls detected on TLC sheet. An aliquot of the $\mathrm{CHCl}_{3}$ fraction $(5 \mathrm{~g})$ was subjected to silica gel open column chromatography $(\mathrm{CC} ; 35 \times 5 \mathrm{~cm} ; 250$ $\mathrm{g}$ ), eluted with $n$-hexane followed by increasing the polarity to pure EtOAc and then to EtOAc:MeOH (50:50, v/v). The resulting CC fractions were analyzed by TLC using different mobile phase ( $n$-Hex:EtOAc 3:7 and EtOAc:MeOH 9:1) and visualizing with anisaldehyde/sulphuric acid reagent followed by heating on a hot plate. The similar CC's fractions on TLC were mixed to afford 12 fractions (Fr. A-L). The well separated fractions on analytical TLCs were selected for further purification using preparative chromatography. Thus, Fr. B $(290.1 \mathrm{mg})$ was loaded onto silica gel flash column chromatography (FCC; 230-400 mesh) eluting with a mixture of $n$-hexane/EtOAc $(90: 10)$, which resulted in six subfractions; SFr. B $1-B_{6}$. Compound $6(43.1 \mathrm{mg})$ was crystalized from $\mathrm{MeOH}$ in $\mathrm{SFr}$. B 3 while Fr. D (336.7 mg) was further purified by silica gel-FCC eluting with $\mathrm{CHCl}_{3}$ :acetone (95:5) to yield nine sub-fractions: SFr. $\mathrm{D}_{1}-\mathrm{D}_{9}$. SFr. $\mathrm{D}_{4}-\mathrm{D}_{6}$ were pooled and re-chromatographed over silica gel FCC using the mobile phase of $\mathrm{CHCl}_{3}: \mathrm{Et}_{2} \mathrm{O} ; 85: 15$ to $70: 30$ to afford compound 7 $(39.4 \mathrm{mg})$. Fr. E (407.6 mg) was triturated using acetone, which is caused to the formation of a white precipitate; compound $\mathbf{8}$ $(61.7 \mathrm{mg})$. The UV quenching spots on TLC plate were detected for the flavonoids compounds in Fr. F-H. Therefore, Fr. F $(279.0 \mathrm{mg})$ was fractionated by FCC silica gel, and eluted with DCM/acetone (90:10) to give six sub-fractions (SFr. $\mathrm{F}_{1-}$ F6). Compound 1 was purified as a yellow powder $(10.3 \mathrm{mg})$ upon triturating SFr. $\mathrm{F}_{4}$ with EtOAc. On the other hand, Fr. G $(173.5 \mathrm{mg}$ ) was subjected to a silica gel FCC and eluted with $\mathrm{CHCl}_{3} / \mathrm{MeOH}$ by increasing the polarity to give five subfractions. The third sub-fraction was subjected to $\mathrm{CC}$ and isocratically washed with $\mathrm{CHCl}_{3} / \mathrm{MeOH}$ yielding the compound $\mathbf{3}(4.8 \mathrm{mg})$. Compounds $4(7.6 \mathrm{mg})$ and $\mathbf{5}(3.9 \mathrm{mg})$ were purified from Fr. H using silica gel-preparative thin layer chromatography (PTLC). Eventually, Fr. K (419.3 mg) was fractionated by silica gel FCC, eluting with gradient of $\mathrm{DCM} / \mathrm{MeOH}$; $95 ; 5$ to $60: 40$ ), resulting eight sub-fractions $\left(\mathrm{SFr} . \mathrm{K}_{1}-\mathrm{K}_{8}\right)$. Amongst, the yellowish sediments of compound $2\left(41.6 \mathrm{mg}\right.$ ) were yielded from the SFr. $\mathrm{K}_{6,7}$ using EtOAc trituration, washing, and filtration procedures.

\subsection{Cytotoxic activity}

The in vitro cytotoxic activity of the extracts and purified compounds (1 and $\mathbf{2}$ ) were examined against MOLT-4 human lymphoblastic leukemia and MCF-7 human breast adenocarcinoma cell lines, respectively, using 3-(4,5dimethylthiazol-2-yl)-2,5-diphenyltetrazolium bromide (MTT) reduction assay $[6,17]$. MCF-7 cells were obtained from Iranian Biological Resource Center, Tehran, Iran, while MOLT-4 cells were purchased from National Cell Bank of Iran, Pasteur Institute, Tehran, Iran. The cells were seeded into 96well microplates and incubated overnight at $37{ }^{\circ} \mathrm{C}$. Three to four different concentrations of plant extracts or isolated compounds were added in triplicate and incubated for another $72 \mathrm{~h}$. The concentration of DMSO in each well did not exceed $0.25 \%$. At the end of the incubation time, the media in each well was replaced with $0.5 \mathrm{mg} / \mathrm{mL}$ MTT dissolved in RPMI without phenol red. After 4 hours at $37{ }^{\circ} \mathrm{C}$ DMSO was added to solubilize the formazan crystals formed inside the viable 
cells. The optical density of the final solution was measured at $570 \mathrm{~nm}$ using a Bio-Tek microplate reader (Model Synergy HTX). The cell viability was calculated compared to untreated control cells by comparison of absorbance measurements. $\mathrm{IC}_{50}$ values for each compound was calculated using CurveExpert software version 1.34 for Windows. Each experiment was repeated 3 to 5 times. Paclitaxel, a standard chemotherapeutic agent, was used as a positive control.

\subsection{DPPH radical scavenging activity}

The in vitro antioxidant activity of compounds $\mathbf{1}$ and $\mathbf{2}$ was determined calorimetrically by assaying for DPPH (2,2diphenyl-1-picrylhydrazyl) radical scavenging activity [7]. Briefly, the plant extracts or isolated compounds were diluted in methanol at five concentrations $\left(78-1250 \mu \mathrm{g} \cdot \mathrm{mL}^{-1}\right)$. Five microliters of each concentration were added to $195 \mu \mathrm{L}$ of DPPH solution $(100 \mu \mathrm{M}$ concentration in $\mathrm{MeOH})$. The microplate was shaken at room temperature in the dark place. After $30 \mathrm{~min}$, the absorbance was measured at $517 \mathrm{~nm}$ using a Bio-Tek microplate reader (Model Synergy HTX). IC 50 values for each components was calculated using CurveExpert software version 1.34 for Windows. Each experiment was repeated 3 times. Quercetin, a pentahydroxy-flavonol, was used as the positive control.

\section{Results and Discussion}

Methanol-water (80:20) extract of the aerial parts of $S$. dracocephaloides after evaporation of its methanol was partitioned between solvents with different polarities; $n$ hexane, chloroform, ethyl acetate, and $n$-butanol. The resulting fractions were evaluated for their cytotoxic effects against MOLT-4 human leukemia cell line as well as DPPH radical scavenging activity. The active chloroform layer was subjected to column chromatography over normal phase silica gel. Consequently, eight reported compounds (1-8) were isolated and characterized (Figure 1). The chemical structures of the isolated compounds 3-8 were elucidated based on comparison of their physical constants such as co-TLC with the reference substances that has been simultaneously isolated from $S$. russellii in our laboratory and their structures were elucidated by ${ }^{1} \mathrm{H}$ and ${ }^{13} \mathrm{C}$ NMR Spectroscopy. Meanwhile, the chemical structures of 1 and 2 were identified as 5-hydroxy-3,6,7,3',4'pentamethoxyflavone and cynaroside (luteolin-7-O- $\beta$-Dglucopyranoside) based on the ${ }^{1} \mathrm{H}$ and ${ }^{13} \mathrm{C}$ NMR spectral data, respectively $[11,12]$. The later compound showed a vast variety of biological activities such as antimalarial, antileishmanial, cytotoxicity, anti-inflammatory and antioxidant activity $[18,19,20]$, while the former $(\mathbf{1})$ has been isolated from the leaves of Vitex negundo acting as anti-allergic constituent [21]. Most of the Polymethoxyflavones (PMFs) have been reported form the Citrus species, from leaves of Murraya spp. (Rutaceae), Kaempferia spp. (Zingiberaceae), and Piper spp. (Piperaceae) [22]. Despite the presence of 5,6,7,8-tetra-oxygeneted flavones among the plants of Lamiaceae family only a few species including Thymus, Salvia, Vitex, and Ocimum appear to accumulate ploymethoxylated flavones [21, 23, 24].

According to the literature survey, Walle reported that the most cytotoxic active flavones are those ones bearing the methoxy groups and concluded that the glycosylation is a crucial effect resulting to be inactive agent on the biological activity [25]. The cytotoxicity against MCF-7 cell lines of compound $\mathbf{1}$ and quercetin are the highest among the tested compounds followed by compound $\mathbf{2}$, respectively (Table 1 ). This is in agreement with the extensive research on the cytotoxicity of PMFs. The higher activity is attributed to the presence of hydroxy group at position C-5 of the PMFs, since 5-hydroxy PMFs exhibited stronger anticancer activity when tested against the colon cancer cells compared to the respective 5-methoxylated derivatives [26]. Salvigenin, eupatorin, and cirsimaritin were isolated from Centaurea kilaea (Asteraceae) in a bioassay-guided purification procedure against two cancerous cell lines; MCF-7 and PC-3; a prostate adenocarcinoma cell line. Only the two later compounds showed potent cytotoxic effect against PC-3 [27, 28]. Quercetin alone or in combination with topotecan showed significant cytotoxicity against the MCF-7 cell lines [29]. While cynaroside showed weak cytotoxic effect against the breast cancer cell line [30]. Literature survey confirmed that polymethoxylated flavonoids like nobiletin, tangeretin, sinensetin, and 5-demethyltangeretin (found in Citrus spp.) play a key role in anticancer and anti-inflammatory activity [21, 22,31 ], as we found for compound $\mathbf{1}$. In addition, the cytotoxic activities of compounds 6-8 have also been previously examined by other investigators against MCF-7 cell line [32, $33,34]$. The radical scavenging activity of quercetin is higher than those measured for compound $\mathbf{1}$ and $\mathbf{2}$ as the following descending order of IC50s: quercetin $\left(5.3 \mu \mathrm{g} \cdot \mathrm{mL}^{-1}\right)>$ cynaroside; 2 (10.7 $\left.\mu \mathrm{g} \cdot \mathrm{mL}^{-1}\right)>$ 5-hydroxy-3,6,7,3',4'pentamethoxyflavone; $1\left(48.8 \mu \mathrm{g} \cdot \mathrm{mL}^{-1}\right)$. Previously, it was reported that glycosylation or methylation of the hydroxy groups decreases the antioxidant activity of flavonoids while the free hydroxy groups together with $3^{\prime}, 4^{\prime}$ dihydroquinol functionality increase it dramatically (supplementary data) [35, 36].

Table 1: Cytotoxic and antioxidant activities of various fractions and pure flavonoids isolated from S. dracocephaloides Boiss.

\begin{tabular}{|c|c|c|c|c|}
\hline \multirow{2}{*}{ Materials } & \multirow{2}{*}{$\begin{array}{l}\text { Weight of the } \\
\text { extract (g) }\end{array}$} & \multicolumn{2}{|c|}{ Cytotoxic activity $\operatorname{IC}_{50}(\mu \mathrm{g} / \mathrm{mL})^{\mathrm{a}}$} & \multirow{2}{*}{$\begin{array}{l}\begin{array}{l}\text { Antioxidant activity } \mathrm{IC}_{50} \\
(\mu \mathrm{g} / \mathrm{mL})^{\mathrm{a}}\end{array} \\
\text { DPPH' radicals }\end{array}$} \\
\hline & & MOLT -4 cells & MCF-7 cells & \\
\hline Aqueous methanol extract & 73.68 & $35.5 \pm 12.2$ & $\mathrm{NA}^{\mathrm{b}}$ & $47.36 \pm 1.89$ \\
\hline$n$-Hexane fraction & 15.35 & $24.6 \pm 8.0$ & NA & NA \\
\hline $\mathrm{CHCl}_{3}$ fraction & 7.26 & $25.8 \pm 6.5$ & NA & $35.76 \pm 4.29$ \\
\hline EtOAc fraction & 6.73 & $31.7 \pm 6.9$ & NA & $57.91 \pm 2.81$ \\
\hline n-BuOH fraction & 14.32 & $35.3 \pm 16.6$ & NA & $76.63 \pm 5.62$ \\
\hline Aqueous fraction & 25.61 & NA & NA & NA \\
\hline $\begin{array}{l}\text { 5-hydroxy-3,6,7,3', } 4^{\prime}- \\
\text { pentamethoxy flavone (1) }\end{array}$ & - & $\mathrm{NT}^{\mathrm{c}}$ & $7.22 \pm 2.95$ & $48.82 \pm 3.43$ \\
\hline Cynaroside (2) & - & NT & $15.48 \pm 2.04$ & $10.74 \pm 2.78$ \\
\hline Quercetin $(\mu \mathrm{g} / \mathrm{ml})$ & - & NT & $7.16 \pm 1.35$ & $5.29 \pm 2.36$ \\
\hline Paclitaxel (ng/ml) & - & $2.4 \pm 0.7$ & $2.49 \pm 0.57$ & - \\
\hline
\end{tabular}

aThe data are presented as mean \pm S.D. of at least three independent experiments. ${ }^{b}$ NA: Not active. ${ }^{c} N T$ : Not tested. Paclitaxel and quercetin were tested as reference agents. 


\section{Conclusion}

To the best of our knowledge, this is the first report of nonvolatile phytochemicals in $S$. dracocephaloides resulting in identification of one PMF (1), further four flavones (2-5), $\beta$ sitosterol and two triterpenoids (6-8). Compound 1 present a rare flavone in Salvia species with five methoxy groups, so far reported in the plants of the Lamiaceae family. Phytochemical investigations on Salvia species revealed that the natural occurrence of 3-methoxy flavones (flavonol-3-methyl-ether) is rare with the expectation of a few compounds including, isokaempferide, kumatakenin, quercetin 3-methyl ether, ayanin, and retusin previously reported [37]. Taken together, the polymethoxyflavones and flavonols could be considered as the chemotaxonomic markers for $S$. dracocephaloides". Likewise, compound $\mathbf{1}$ acted as a potent cytotoxic agent while weakly scavenged the free stable radicals of DPPH that showed the activities are not follow the same mechanisms of action.

\section{Acknowledgments}

The authors are grateful to Golestan University and Shiraz University of Medical Sciences for the financial support. We especially thankful to Dr. Mojtaba Asadollahi and Mr. Mehdi Zare for their skillful collection and identification of the plant material. This article is a part of the $\mathrm{PhD}$ dissertation submitted to the Department of Chemistry (Golestan University, Gorgan, Iran), for the fulfillment of the $\mathrm{PhD}$ degree of Salar Hafez Ghoran in Phytochemistry.

\section{Authorship contribution statement}

Conceptualization, Investigation, Methodology, Roles/Writing - original draft: S. Hafez Ghoran. Conducted experiments: S. Hafez Ghoran, A.R. Jassbi. Writing - review \& editing, Validation, Supervision: O. Firuzi, A.R. Jassbi. All the authors approved the final version of the manuscript.

\section{Conflict of interest}

The authors declare they have no any competing interest.

\section{References}

1. Hedge I. Salvia L. Flora of Turkey and the East Aegean islands. 1982;7:400-461.

2. Jamzad Z, Asadī M. "Lamiaceae. Research Institute of Forests and Rangelands; 2012

3. Mozaffarian V. A dictionary of Iranian plant names: Latin, English, Persian. Farhang Mo'aser; 2003

4. Jassbi AR, Zare S, Firuzi O, Xiao J. Bioactive phytochemicals from shoots and roots of Salvia species. Phytochemistry reviews. 2016;15(5):829-867.

5. Wu YB, Ni ZY, Shi QW, Dong M, Kiyota H, Gu YC, Cong B. Constituents from Salvia species and their biological activities. Chemical Reviews. 2012;112(11):5967-6026.

6. Asadollahi M, Firuzi O, Jamebozorgi FH, Alizadeh M, Jassbi AR. Ethnopharmacological studies, chemical composition, antibacterial and cytotoxic activities of essential oils of eleven Salvia in Iran. Journal of Herbal Medicine. 2019;17:100250.

7. Firuzi O, Miri R, Asadollahi M, Eslami S, Jassbi AR. Cytotoxic, antioxidant and antimicrobial activities and phenolic contents of eleven Salvia species from Iran. Iranian Journal of Pharmaceutical Research: IJPR. 2013;12(4):801-810.

8. Kotan R, Kordali S, Cakir A, Kesdek M, Kaya Y, Kilic H. Antimicrobial and insecticidal activities of essential oil isolated from Turkish Salvia hydrangea DC. ex Benth. Biochemical Systematics and Ecology. 2008;36(5-6):360-368.

9. Jamzad M, Hafez-Taghva P, Kazembakgloo A, Jamzad Z. Chemical composition of essential oil, total flavonoid content and antioxidant activity of Salvia dracocephaloides Boiss. from Iran. Journal of Essential Oil Bearing Plants. 2014;17(6):1203-1210.
10. Rustaiyan A, Masoudi S, Jassbi AR. Essential Oil of Salvia hydrangea DC. ex Benth. Journal of Essential Oil Research. 1997;9(5):599-600.

11. Martínez V, Barberá O, Sanchez-Parareda J, Marco JA. Phenolic and acetylenic metabolites from Artemisia assoana. Phytochemistry. 1987;26(9):2619-2624.

12. Blunder M, Orthaber A, Bauer R, Bucar F, Kunert O. Efficient identification of flavones, flavanones and their glycosides in routine analysis via off-line combination of sensitive NMR and HPLC experiments. Food Chemistry. 2017;218:600-609.

13. Alwahsh MA, Khairuddean M, Chong WK. Chemical constituents and antioxidant activity of Teucrium barbeyanum Aschers. Records of Natural Products. 2015;9(1):159-163.

14. Nagao T, Abe F, Kinjo J, Okabe H. Antiproliferative constituents in plants 10. Flavones from the leaves of Lantana montevidensis B RIQ. and consideration of structure-activity relationship. Biological and Pharmaceutical Bulletin. 2002;25(7):875-879.

15. Saeidnia S, Manayi A, Gohari AR, Abdollahi M. The story of betasitosterol-a review. European Journal of Medicinal Plants. 2014;4(5):590-609.

16. Martins D, Carrion LL, Ramos DF, Salomé KS, da Silva PE, Barison A, Nunez CV. Triterpenes and the antimycobacterial activity of Duroia macrophylla Huber (Rubiaceae). BioMed Research International. 2013 Oct;2013.

17. Hafez Ghoran S, Babaei E, Rezaei Seresht H, Karimzadeh Z. Cytotoxic constituents and molecular docking study of the active triterpenoids from Tripleurospermum disciforme (C. A. Mey.) Schultz-Bip. Jundishapur Journal of Natural Pharmaceutical Products. 2020;15(2):e65760.

18. Calixto JB, Campos MM, Otuki MF, Santos AR. Antiinflammatory compounds of plant origin. Part II. Modulation of pro-inflammatory cytokines, chemokines and adhesion molecules. Planta Medica. 2004:70(2):93-103.

19. Kirmizibekmez H, Calis I, Perozzo R, Brun R, Donmez AA, Linden A, Rudi P, Tasdemir D. Inhibiting activities of the secondary metabolites of Phlomis brunneogaleata against parasitic protozoa and plasmodial enoyl-ACP reductase, a crucial enzyme in fatty acid biosynthesis. Planta Medica. 2004;70(8):711717.

20. Saracoglu I, Varel M, Harput US, Nagatsu A. Acylated flavonoids and phenol glycosides from Veronica thymoides subsp. pseudocinerea. Phytochemistry. 2004;65(16):2379-2385.

21. Patel J, Deshpande SS. Anti-Allergic and antioxidant activity of 5Hydroxy-3,6,7,3',4'-pentamethoxy flavone isolated from leaves of Vitex negundo. Anti-Inflammatory \& Anti-Allergy Agents in Medicinal Chemistry (Formerly Current Medicinal ChemistryAnti-Inflammatory and Anti-Allergy Agents). 2011;10(6):442-451.

22. Tung YC, Chou YC, Hung WL, Cheng AC, Yu RC, Ho CT, Pan MH. Polymethoxyflavones: Chemistry and molecular mechanisms for cancer prevention and treatment. Current Pharmacology Reports. 2019;5(2):98-113

23. Berim A, Gang DR. Methoxylated flavones: occurrence, importance, biosynthesis. Phytochemistry Reviews. 2016;15(3):363-390

24. Tomás-Barberán F, Wollenweber E. Flavonoid aglycones from the leaf surfaces of some Labiatae species. Plant Systematics and Evolution. 1990;173(3-4):109-118.

25. Walle T. Methoxylated flavones, a superior cancer chemopreventive flavonoid subclass? Seminars in cancer biology. 2007;17(5):354-362.

26. Qiu P, Dong P, Guan H, Li S, Ho CT, Pan MH, McClements DJ, Xiao H. Inhibitory effects of 5-hydroxy polymethoxyflavones on colon cancer cells. Molecular Nutrition \& Food Research. 2010:54(S2):S244-S252

27. Sen A, Ozbas Turan S, Bitis L. Bioactivity-guided isolation of antiproliferative compounds from endemic Centaurea kilaea. Pharmaceutical Biology. 2017;55(1):541-546.

28. Kouhbanani MA, Beheshtkhoo N, Amani AM, Taghizadeh S, Beigi V, Bazmandeh AZ, Khalaf N. Green synthesis of iron oxide nanoparticles using Artemisia vulgaris leaf extract and their application as a heterogeneous Fenton-like catalyst for the degradation of methyl orange. Materials Research Express. 2018;5(11):115013.

29. Akbas SH, Timur M, Ozben T. The Effect of Quercetin on Topotecan Cytotoxicity in MCF-7 and MDA-MB 231 Human 
Breast Cancer Cells1. Journal of Surgical Research. 2005;125(1):49-55.

30. Mamadalieva NZ, Herrmann F, El-Readi MZ, Tahrani A, Hamoud R, Egamberdieva DR, Azimova SS, Wink M. Flavonoids in Scutellaria immaculata and S. ramosissima (Lamiaceae) and their biological activity. Journal of Pharmacy and Pharmacology. 2011;63(10):1346-1357.

31. Manthey JA, Guthrie N, Grohmann K. Biological properties of Citrus flavonoids pertaining to cancer and inflammation. Current Medicinal Chemistry. 2001;8(2):135-153.

32. Chakravarti B, Maurya R, Siddiqui JA, Bid HK, Rajendran SM, Yadav PP, Konwar R. In vitro anti-breast cancer activity of ethanolic extract of Wrightia tomentosa: role of pro-apoptotic effects of oleanolic acid and urosolic acid. Journal of Ethnopharmacology. 2012;142(1):72-79.

33. Kassi E, Sourlingas TG, Spiliotaki M, Papoutsi Z, Pratsinis H, Aligiannis N, Moutsatsou P. Ursolic acid triggers apoptosis and Bcl-2 downregulation in MCF-7 breast cancer cells. Cancer investigation. 2009;27(7):723-733.

34. Awad AB, Chinnam M, Fink CS, Bradford PG. $\beta$-Sitosterol activates Fas signaling in human breast cancer cells. Phytomedicine. 2007;14(11):747-754.

35. Jassbi AR, Singh P, Krishna V, Gupta PK, Tahara S. Antioxidant study and assignments of NMR spectral data for $3^{\prime}, 4^{\prime}, 7$ trihydroxyflavanone $3^{\prime}, 7$-di-O- $\beta$-D-glucopyranoside (butrin) and its hydrolyzed product. Chemistry of Natural Compounds. 2004;40(3):250-253.

36. S Tuzun B, Hajdu Z, Orban-Gyapai O, P Zomborszki Z, Jedlinszki N, Forgo P, Kivcak B, Hohmann J. Isolation of chemical constituents of Centaurea virgata lam. and xanthine oxidase inhibitory activity of the plant extract and compounds. Medicinal Chemistry. 2017;13(5):498-502.

37. Lu Y, Foo LY. Polyphenolics of Salvia-a review. Phytochemistry. 2002;59(2):117-140. 